Social Work/Maatskaplike Werk Vol 57 No 2; Issue 8

http://socialwork.journals.ac.za/pub

doi:http://dx.doi.org/10.15270/52-2-932

Zibonele France Zimba

Dr Zibonele France Zimba, Department of Social Work, Stellenbosch University, Stellenbosch, South Africa.

For more than three decades in the field of social work the focus has been on social workers and persons living with disabilities. The purpose of this article is to present the findings of an empirical study on practice experiences of social workers living with disabilities in South Africa. A qualitative research methodology was used to achieve the objective of the study. Data were collected through semi-structured one-on-one interviews with seven social workers living with disabilities. The findings of the study revealed that social workers with disabilities consider their experiences in practice as both positive and negative. The study also revealed that participants experience challenges in practice.

Keywords: disabilities, people with disabilities, practice experiences, social model, social workers, support 



\title{
PRACTICE EXPERIENCES OF SOUTH AFRICAN SOCIAL WORKERS LIVING WITH DISABILITIES
}

\section{Zibonele France Zimba}

\author{
Dr Zibonele France Zimba, Department of Social Work, Stellenbosch University, Stellenbosch, \\ South Africa.
}

Keywords: disabilities, people with disabilities, practice experiences, social model, social workers, support

\section{INTRODUCTION}

The World Health Organization (WHO) reported that 15 percent of the world's population lives with some form of disability (World Health Organization, 2011). The Community Survey of Statistics South Africa in 2016 estimated that 7.7 percent of South Africans lived with a disability (Statistics South Africa, 2016). The latest available census data indicate that 5.3 percent of persons living with a disability attained higher education compared to 22.3 percent of non-disabled individuals (Statistics South Africa, 2014). Furthermore, only 1 percent of disabled persons are employed compared to 73.3 percent of non-disabled persons (Statistics South Africa, 2016). Several studies have indicated that people with disabilities experience various challenges in their workplace within different employment settings. In hospitality, people with disabilities experience discrimination from hotel management based on their physical appearance (Donnelly \& Joseph, 2012). In public organisations, people with disabilities are reported to face career advancement challenges, which include lack of promotion, training and enhancement of skills (Ximba, 2016). In medical practice, physicians with disabilities encounter challenges of being mistaken as patients (Blauwet, 2018, Mccoll, Foster, Shortt, Hunter, Dorland, Godwin \& Rosser, 2008).

In social work research and debates the focus has been on service users living with disabilities, since a large sector of social work service users are people with disabilities, yet few are working as social workers (Crawshaw, 2010). Furthermore, the literature indicates that it is not known how many social workers in South Africa are living with disabilities. An Australian study found that social workers with disabilities in their capacity as field supervisors experience conflicting notions of being role models for others (Healy, Tillotson, Short \& Hearn, 2015). A study in the United Kingdom reported that workers with disabilities face discrimination by their employers for disclosing their mental illness (MacDonaldWilson, Russinova, Rogers, Lin, Ferguson, Dong \& Macdonald, 2011). A survey conducted in the United States indicated that social workers with disabilities are faced with discrimination because of their disability (Freidel, 1997). It is apparent from the literature on social workers with disabilities in other countries face various challenges in practice.

For more than three decades there has been a very comprehensive discussion in social work circles of disabilities and the role of social work towards people living with disabilities (Escamilla, 2017). Research has been conducted on views and perceptions of social workers regarding the support systems needed by social workers in practice. Most of these studies indicate that social workers require personalised professional support, a working environment conducive to meeting their needs, regular educational supervision, and continuous training and guidance (Dlangamandla, 2010,Mashigo, 2007). However, no studies have rigorously investigated the perspectives of social workers with disabilities on the kinds of support they require for their optimal functioning. A study revealed the views of disabled workers on the types of employment support required in practice (Lewis, Dobbs \& Biddle, 2013).

\section{PROBLEM STATEMENT AND AIM OF THE STUDY}

There have been no studies conducted in South Africa to explore the practice experiences of social workers living with disabilities. A survey was conducted in California in the USA in 1997 which focused on work experiences of practising social workers who are disabled (Freidel, 1997). There is also literature 
on social work students with disabilities in Scotland and their barriers to training (Baron, Phillips \& Stalker, 1996). Some of these barriers included the disabling physical environment in institutions of higher learning regarding access to buildings. It is not known if South African social workers with disabilities face additional barriers to optimal functioning in their jobs. Regardless, many scholars argue that people with disabilities experience additional challenges at their workplace compared to nondisabled people (Healy et al., 2015). Therefore, the purpose of this study was to explore practice experiences of South African social workers living with disabilities.

\section{RESEARCH QUESTION AND OBJECTIVE}

The research question is the starting point for the research process and facilitates the determination of the goal (Royse, 2008). The principal research question for this study was: What are the practice experiences of South African social workers living with disabilities? The researcher thus wanted to achieve the objective of gaining insight into the practice experiences of South African social workers living with disabilities.

\section{UNDERSTANDING DISABILITY IN THE CONTEXT OF EMPLOYMENT USING THE SOCIAL DISABILITY MODEL}

Disability is complex, dynamic, multidimensional and contested concept (World Health Organization, 2011). In the South African context the Employment Equity Act, No. 55 of 1998, considers the term "disability" in the context of "people with disabilities", meaning people who have a long-term or recurring physical or mental impairment which substantially limits their prospects of entry into, or advancement in, employment (Republic of South Africa, 1998:10). Various models are used to understand disability; for the purpose of this study the social model will be used.

The social model views disability mainly as a socially created problem preventing the full integration of persons with disabilities into society and the workplace (Van Staden, 2011:62). Disability is not an attribute of an individual, but rather a complex collection of conditions, many of which are created by social and work environments. The social model of disability proposes that constraints, prejudice and exclusion by the community are the ultimate factors defining who is disabled and who is not in a society. The social model recognises that while some persons have physical, intellectual or psychological differences, which may sometimes be impairments, these differences do not have to result in disability, unless the community fails to accommodate and include them in the way it would those who are "normal" (Van Staden, 2011:64).

This study focuses on the key characteristics of the social disability model as cited by Van Staden (2011:57), adopted from Kaplan (2000). These key characteristics are:

knowledge base - this indicates the origin of the model and allows an understanding of the principles underlying the relevant approach;

roles - this refers to the context or source of the relevant model and the roles which operate within this context;

rules and relationships - this refers to the way in which policies and practices are developed and how role-players interact; and

shortcomings - this refers to the shortcomings and criticisms of the model.

\section{METHODOLOGY}

This qualitative study sought to investigate the practice experiences of South African social workers living with disabilities by describing and understanding the experiences of these social workers (Babbie \& Mouton, 2010). Exploratory and descriptive research designs were utilised in this study. The exploratory and descriptive research designs were employed to allow for the opportunity to engage with and share the experiences of social workers living with disabilities. Kumar (2005) states that exploratory 
research is utilised with the aim of investigating an area that has not been studied before, or where little is known about the phenomenon under study. A descriptive research design is used to provide detail and paint a picture of a situation, thus focusing on "how" and why" questions (Schurink, Fouché \& De Vos, 2011). The study employed mainly purposive sampling, complemented with snowball sampling, to collect data in one-on-one interviews with social workers $(n=7)$ living with disabilities in all provinces in South Africa. Strydom and Delport (2011 citing Monette, Sullivan \& Dejong, 2005) note that purposive sampling is based entirely on the judgement of the researcher, in that the sample is composed of elements that are the most characteristic and representative of the population that serve the purpose of the study. The study used the purposive sampling technique for sampling social workers living with disabilities, because social workers living with disabilities have the characteristics that would support achieving the objective of the study. Snowball sampling is a sampling technique that is normally used when there is no knowledge of the sampling frame and limited access to appropriate participants for the intended study (Alston \& Bowles, 2003 cited in Strydom \& Delport, 2011). This study used snowball sampling utilised because statistics and knowledge on the total number of social workers living with disabilities in South Africa is not known.

Participants in the study were recruited using two approaches. The first was to contact non-profit organisations (NPOs) and government organisations across South Africa that employ social workers to seek permission to inform and invite these social workers to participate in the study. The sampling method used to select NPOs and government organisations was target sampling. According to Strydom (2011), target sampling involves the researcher compiling a list of names by means of careful questioning in the community until enough possible participants have been identified. Once permission was granted, an invitation email was sent to all the social workers informing them about the study. The invitation stated the purpose of the study and the criteria for inclusion in the study. The second approach to recruitment of participants was the use of professional network contacts to invite social workers living with disabilities to participate in the study. This approach involved sending an email invitation to professional social workers living with disabilities who are part of disability organisations.

The criteria for inclusion of the sample in the study were that participants must be a qualified social worker, currently registered as a social worker with the South African Council for Social Service Professions (SACSSP), consider themselves as a person with a disability, and have worked or working as a social worker for more than six months. Social workers who met the criteria of inclusion contacted the researcher to participate in the study, and the researcher in turn contacted them to explain the purpose and the procedures of the study. Participants were asked to suggest a method of signing the informed consent form based on their abilities. Consent to participate in the study was gained by either signing a letter of informed consent or by giving verbal consent using a digital recorder during the interviews. Participants were informed that they could withdraw at any stage of the research without any consequences. Participants were given the assurance that the information and responses shared during the interviews would be presented as anonymous in order to protect their identity. At the end of each interview participants were asked to suggest colleagues they knew who met the criteria. The researcher contacted the suggested potential participants, then the data collection process resumed. Ethics approval for the study was obtained from Stellenbosch University Research Ethics Committee.

Semi-structured one-on-one interviews were carried out with seven social workers living with disabilities in South Africa using an interview schedule with open-ended questions. These interviews allowed participants to have the freedom to digress and introduce their own issues during the interviews. De Vos, Strydom, Fouché and Delport (2011) state that semi-structured one-on-one interviews are used primarily to get a clear picture of participants' convictions about a specific topic. Thematic analysis was used for the data analysis, as suggested by Bryman (2012). This involved scanning of the raw data, which were transcribed, arranged and organised for analysis. This also allowed for scanning of incomplete, inaccurate, inconsistent and/or irrelevant data in order to organise data into relevant categories. Data were organised into a manageable format or into groups in terms of descriptions, common words, phrases, themes or patterns of information, which were categorised according to smaller relevant pockets of 
information (Braun \& Clarke, 2006). Tabulation was the best format for representing the data in ways that provided meaningful summaries and interpretations, and by selecting quotations from the responses to questions posed during the face-to-face interviews.

Steps recommended by Creswell (2009) were followed to transcribe verbatim all the audio-recorded responses to the interview questions. The researcher listened to the audiotapes, and read and re-read all the transcriptions. The process was followed for the body of data, then significant statements pertaining to the participants' experiences were extracted, a list of topics was compiled, and similar topics were clustered together. Descriptive words for the topics were assigned and turned into categories. Topics that were related were grouped together. Statements were then organised into themes and sub-themes. Subthemes were used to provide full descriptions of the participants' experiences.

\section{RESULTS AND DISCUSSION OF THE FINDINGS}

The results and discussion of the study are divided into two sections. The first section is the biographical information of participants; the second section focuses on the themes and sub-themes that emerged from the narratives of the participants. Pseudonyms were used to protect the confidentiality and anonymity of the study participants.

TABLE 1

BIOGRAPHICAL INFORMATION OF THE PARTICIPANTS

\begin{tabular}{|l|l|l|l|}
\hline Pseudonym & Years of practice & Name of disability & Cause of disability \\
\hline Participant A & 05 & Spinal cord injury & Motor Accident \\
\hline Participant B & 11 & Hyperopia & Biological \\
\hline Participant C & 07 & Leg length discrepancy & Biological \\
\hline Participant D & 02 & Myopia & Biological \\
\hline Participant E & 30 & Aphasia & Food Lifestyle \\
\hline Participant F & 08 & Multiple sclerosis & Biological \\
\hline Participant G & 01 & Spinal cord injury & Biological \\
\hline
\end{tabular}

Social workers living with disabilities who participated in the study had been in practice as social workers for between one year and thirty years. The literature suggests that the process of transition from university social work education to the workplace needs to be managed to allow newly appointed social workers to fully settle in (Bradley, 2008). The inclusion of social workers living with disabilities who had been practising longer than six months to a year or more influenced the study positively, as these participants seemed to be more settled in their workplace. Social workers who participated in the study were living with different types of disabilities. Out of the seven participants, two mentioned spinal cord injury, and the other five mentioned light perception, leg length discrepancy, functional blindness, aphasia and multiple sclerosis. The Statistics South Africa (2016) Community Survey indicates that about 2,5 percent of persons in South Africa reported having mild difficulty in walking, while 1 percent reported having severe difficulty in walking a kilometre or climbing a flight of stairs. About 51 percent of persons in South Africa between the age of 9 and 85 years reported having difficulties with their sight (Statistics South Africa, 2016).

The majority of the participants mentioned that their disability was diagnosed as having a biological aetiology. Abdalla, Apramian, Cantley and Cullen (2017) indicate that higher rates of disability have been attributed to work-related injuries and greater risk-taking behaviour. It has also been noted that causes of disability vary between sexes. Women are less likely to become disabled as a consequence of injury, but are more likely to become disabled as a result of chronic illness. As a result of increased longevity and increasingly unhealthy lifestyle choices, middle-aged and elderly women tend to be seriously affected by chronic diseases. This finding is in line with the findings by Van Staden (2011) that a person can be disabled from birth due to a genetic disorder, or complications during birth or substance abuse by the mother, but is can also be acquired as a result of an accident, attempted suicide, a gunshot 
wound or a medical condition. However, the study did not explore issues of gender as it was not interested in the relationship between gender and the cause of disability.

The second section of the findings and discussion present data categorised according to different themes that emerged from the interviews. The data yielded three main themes, as indicated below:

- Theme 1: Practice experiences as a social worker living with a disability;

- Theme 2: Challenges experienced by social workers living with disabilities in the workplace;

- Theme 3: Types of support available to social workers in practice.

\section{Theme 1: Practice experiences as a social worker living with a disability}

Kwan and Reupert (2019) stated that experiences of social workers were found to be associated with their motivation to work with certain clients, in the way they practise, as well as the intervention goals they pursue. Two sub-themes emerged on the practice experiences of social workers living with a disability, as discussed below.

\section{Sub-theme 1.1: Positive practice experience}

Participants in the study were asked to describe their practice experiences as social workers in practice. Four of the seven participants related that their experience in practice as social workers was positive. Their views were as follows:

I consider my practice experience as positive, the colleagues I work with never treat me different due to my disability, I feel encouraged to work in this environment. I am encouraged by colleagues to be creative on tasks and strive to be an outstanding professional social worker. (Participant D)

The above finding reflects that social workers living with disabilities find their practice experience as positive with encouraging colleagues. The findings of this study are in line with findings by Gustafsson, Peralta and Danermark (2014) that employees experience their working environment as positive when employees with disabilities are seen as ordinary rather than unusual. Additionally, other participants considered their practice experience as positive because of considerate decision-making processes and work agreement adjustments by their employers or line managers/supervisors (Gustafsson et al., 2014). These seem to be the experiences of both employers and fellow colleagues in providing a welcoming environment in the workplace for people with disabilities, functioning in this respect as a door opener to the labour market. Copeland, Chan, Bezyak and Fraser (2010) argue that positive attitudes and experiences are often shown by colleagues in a working environment and are related to experiences of working with people who understand people with disabilities. From the social disability model point of view, discrimination is inherent in the way society thinks and operates. This finding suggests that the cure to the problems associated with disability lies in rectifying the views expressed in society. This assertion is in line with Van Staden (2011), who argued that dealing with social disability entails moving away from viewing persons with disabilities as problems to seeing them as holders of rights.

\section{Sub-theme 1.2: Negative experience}

All social workers living with disabilities who participated in the study during the interviews also highlighted that they had negative experiences in their practice. The participants mentioned that the negative experiences were related to attitudes shown by colleagues in the workplace. Social workers with disabilities reported that colleagues in the workplace have negative perceptions of the needs of people living with disability. One participant said:

Some of my colleagues have perception that I cannot do things for myself, they want to do everything for me or pity me for my disability. Additionally, Ifeel like this perception makes me excluded from camaraderie. (Participant A)

The findings on the negative experiences of social workers living with disabilities indicate that colleagues in the workplace demonstrate negative perceptions of the needs of persons with disability. Ximba (2016, 
citing Zunker, 2006) states that employers avoid recruiting candidates with disabilities because of fear of negative reactions towards people with disabilities by their colleagues. This assertion is confirmed by the finding of this study that colleagues of social workers with disabilities show negative perceptions which create negative experiences. Some participants consider their practice experience as negative because of their colleagues' cultural and religious beliefs regarding disabilities. Participant H said:

Some colleagues in my office uses cultural and religious remarks on their understanding about disabilities, like saying their cultural and religious belief is that disability is a sign of curse and witchcraft. Such remarks are made in a light way, but it makes me feel that my workplace is negative.

Potgieter, Coetzee and Ximba (2017) reported that negative beliefs are perpetuated by cultural practices which segregate people with disabilities from mainstream society. Other authors argue that in a workplace the colleagues and supervisors who work with persons living with disabilities are the greatest source of these discriminatory practices, because negative stereotypes or prejudices form invisible barriers which limit their potential and adversely influence their self-esteem. A survey conducted in the USA on the work experiences of practising social workers who are disabled reported that 28 percent of social workers with disabilities who responded in the survey indicated fear of discrimination, stigma, prejudice and being treated differently in the workplace once others know of their disability (Freidel, 1997). This finding of the study concurs with the conclusions arrived at by Albert (2004:8) that discrimination regarding disability is very often based on cultural and religious reasoning. The social model of disability represents a strong challenge to traditional thinking about disability (Oliver, 1983). However, this study did not establish whether colleagues' negative experiences originated from the reactions of other professional social workers or all personnel in the organisation.

\section{Theme 2: Challenges experienced in practice by social workers living with disabilities}

Various studies confirmed that persons with disabilities in the workplace encounter challenges (Hargreaves, Dearnley, Walker \& Walker, 2014; Jayasooria, Krishnan \& Ooi, 1997; Ta \& Leng, 2013; Malatji \& Dube, 2017; Nhedzi \& Makofane, 2015; Potgieter et al., 2017)

However, the findings of this study focused on challenges experienced in practice by social workers living with disabilities. The data analysed yielded a number of sub-themes.

\section{Sub-theme 2.1: Infrastructure in the workplace and community}

All participants in the study mentioned that one of the main challenges experienced in practice is related to infrastructure in their workplace and the communities they serve. One of the participants said:

The challenge I experience with my disability in practice, particularly in the workplace, is to access some of the offices with my wheelchair, also when I attend community meetings and home visits, I cannot have access to all parts of the community and houses with my wheelchair. (Participant F)

The findings of the study indicate that social workers with disabilities in practice experience challenges related to infrastructure, lack of access to facilities in the work environment, communal access problems with no paving, and households with no access for person using wheelchairs. Other studies found that employees with disabilities experience architecturally barrier-free environments to enable them to get to their workplace (Jayasooria et al., 1997). The findings also reveal that social workers living with disabilities experience challenges of access to communities while doing home visits and community meetings. This finding is confirmed by conclusions drawn in Potgieter et al. (2017) that persons with disabilities in the workplace experience challenges related to geographical design and landscapes. This finding further affirms the premise of the social disability model that the problem is located within society rather than within the individual with a disability. Therefore, infrastructure in the workplace and the community fails when it is not inclusive of persons living with disabilities. This finding thus provides a strong argument for the fundamental aspect of the social disability model which is concerned with equality and accessibility (Oliver, 1983). 


\section{Sub-theme 2.2: Organisational management}

The majority of the participants in the study mentioned that they experience challenges in practice at organisational management level. Social workers living with disabilities in practice found organisational management to be challenging in their practice. Participants mentioned that organisational management does not prioritise their budgets and policies for an inclusive infrastructural environment. One participant said:

In my organisation, the management does not set funds for renovating the building to be fully accessible to all people living with disabilities; since the building has a wheelchair ramp, it is as if that's enough, [but] the building is not accessible for blind persons. (Participant G)

The findings above reflect that organisational management creates an environment which is challenging for social workers living with disabilities in practice. Potgieter et al. (2017) assert that management can play an active role in transforming organisations by changing perceptions of candidates with disabilities. However, the findings of the study indicate that the transformation of organisations must be an deliberate step to create an inclusive environment; such transformation must be reflected in organisational policies and financial plans. Wegner (2011) concedes that employing people with disabilities may be beneficial, but also acknowledges challenges facing people with disabilities in the workplace such as the ignorance and biases held by employers. Other social workers living with disabilities mentioned that organisational managements are impatient with them regarding flexibility of working hours which results in disparaging comments. One participant said: "My line manager often complains that I take long to produce reports and do work" (Participant E).

The findings above show that social workers with disabilities experience challenges with finishing work on time and that management is often is not satisfied with this. This finding confirms an argument made by Bonaccio, Connelly, Gellatly, Jetha and Martin-Ginis (2020), who reported that managers may express concerns about workers with disabilities' performance and safety behaviours, low productivity and frequent absence. Additionally, Van Staden (2011) found that managers are not trained in managing the performance of persons with disabilities. The finding on organisational management is indicative of the argument posed by the social disability model that rules are determined within a framework of choice and independent living with strong support from organised disability communities.

\section{Sub-theme 2.3: Use of professional skills in practice}

The majority of social workers living with disabilities who participated in the study mentioned that one of their practice experiences is related to the use of professional skills in practice. Participants identified the use of observation skills and communication skills. Participant B is quoted below:

I have a visual impairment, I struggle to see clear, most of the time I see blurry and it takes time for me to have focus in an object. I experience difficulties to observe during practice.

Participant B further added:

Also, I experience difficulties to assess environments in a distance or see non-verbal cues far when talking to colleagues or facilitating a meeting.

The findings above reflect that social workers living with disabilities experience challenges in using professional skills in practice. Old (2017) argues that observation skills can be even harder, especially if much of this work takes place implicitly throughout social workers' training and field placements. Social workers living with visual impairment disabilities find it difficult to utilise effective observation in practice which enables them to plan for an appropriate intervention and enhance their practice (Nelson, 2015). Another social worker living with aphasia, which affected the social worker's ability to communicate, mentioned that the challenge is using communication skills during meetings and interviews with clients. The participant said: 
As you could hear, I have a challenge to communicate audible, this becomes an issue when I am in a meeting expressing myself, sometime people do not hear me. I think it's a skill that I should have as a social worker. (Participant E)

The finding above shows that social workers living with disabilities related to restrictions to communicate experience practice challenges in executing communication skills. Farukuzzaman and Rahman (2019) contest that communication is a vital element that plays an important part in direct social work practice to promote, enhance and ensure social welfare services for individual, group and community clients with a diversity of problems across societies. The findings of the study reveal that using verbal communication in social work practice when living with a disability that restricts verbal communication is a challenge. Challenges of this kind must be seen within the context of the social disability model, which purports that disability is not an attribute of an individual, but rather a complex collection of conditions, many of which are created by social and work environments (Oliver, 1983).

\section{Theme 3: Types of support available to social workers in practice}

The literature on disabilities shows that work environments of persons living with disabilities set up support services (Potgieter et al., 2017; Bonaccio et al., 2020). The theme yielded two sub-themes, as discussed below.

\section{Sub-theme 3.1: Human resource support}

All participants in the study indicated that one type of support available in practice is human resources support. One participant indicated that one of the major supports available from human resource is recruitment, induction and work-related help during employment. Participants also indicated that human resource personnel are professionals at the forefront of advocating for inclusivity of persons with disabilities. One participant explained:

The human resources division has been with me since I started working as a social worker, anything I do not understand, the human resources always engage with me and my supervisor about my adaptability at work. (Participant G)

The findings above reveal that the human resources personnel are an integral support for social workers living with disabilities in practice. The findings of the study confirm an assertion made by Bonaccio et al. (2020) that human resource departments are vital in proving support to persons with disability from the time of their recruitment. Gida and Ortlepp (2007) emphasise that the human resources departments are entrusted with integrating people with disabilities into the workplace with human resource interventions. Kulkarni and Valk (2010) argued that support for person with disabilities in the workplace falls under the purview of the human resources function. One participant added: "Most of the support I receive is from human resources. I would like to receive more support from my professional supervisor" (Participant D).

The findings above indicate that most of the support social workers with disabilities receive is from the human resources department rather than their line managers and supervisors. The literature consulted focused on social work and services provided to person with disabilities and supervision for social workers; Goliath, 2018; Mak, 2013). One study by Healy et al. (2015) focused on social work field education and believing in supervisors who are living with disabilities. However, the study did not investigate supervision provided to the supervisors in social work practice who are living with disabilities. Oliver (1983) states that, in the social disability model, rules are determined within a framework of choice and independent living with strong support from organised disability communities. Based on this premise, the support offered by the human resources department is an indication that organisational rules are used to provide environmental support to social workers living with disabilities. 


\section{Sub-theme 3.2: Open support networks}

The majority of social workers living with disabilities identified open support networks as one of the supports available. The participants indicated that the support services come from the practice environment and available in social settings. One participant said:

\section{I have a support network which is open for me to attend anytime I wish to go and network with other individuals with disabilities. The group is not in the workplace. (Participant F)}

The results above reveal that social workers living with disabilities get support from support networks out of the work environment. The importance of the support group lies in creating networking opportunities with others. Bezerra, Paulo, Suely and Silva (2015) mention that support networks greatly enhance the chances of the disabled person to become involved in different social groups. Support for people with disabilities is vital in assisting with tasks that promote community living and integration across the life course (Grossman \& Magaña, 2016). This finding of the current study concurs with the literature that support networks for social workers living with disabilities is paramount for functioning. Mendes de Leon, Gold, Glass, Kaplan and George (2001) argue that the idea of social networks and support is that they are based on social constructions which focus on social interaction with close contact (families) and open contact (colleagues and community). Oliver (1983) states that the social disability model is focused on strong support from organised disability communities.

\section{CONCLUSION AND RECOMMENDATIONS}

Based on the literature consulted and the findings of the study, it can be concluded that, for decades, the social work profession has been involved with persons living with disabilities. Yet little debate and few studies have been conducted on social workers living with disabilities and their practice experiences. Considering this evidence, understanding the scope of social workers living with disabilities is vital for the social work profession's quest for social justice. The findings of the study on the challenges posed by using theoretical skills in practice, such as observation skills and communication skills for social workers living with disabilities, reveal an opportunity to ask critical questions about the theoretical foundations of social work and inclusivity.

Based on the research findings, the a number of recommendations are made, grouped according to practice and the needs for future research.

Practice: The study recommends that social work NPOs and government organisations must transform infrastructurally in order to achieve universal access for social workers living with disabilities, thus benefitting both practitioners and clients with disabilities. Practice must mobilise and motivate communities to build and create inclusive environments for persons with disabilities. The study recommends that organisational management must formulate organisational policies that protect social workers living with disabilities against any form of negative treatment. The study recommends that organisational management can use positive and acceptable practices to raise awareness about disabilities in the workplace. The study recommends that human resources departments of NPOs and government organisations must organise training for staff and supervisors in ways to promote disability inclusion in the workplace.

Future research: The study recommends that a survey be conducted to establish the total number of social workers living with disabilities who are in practice or not. The study recommends that future research explore the experiences of social workers living with disabilities regarding their clients' attitudes towards them.

\section{REFERENCES}

ABDALLA, S., APRAMIAN, S.S, CANTLEY, L.F. \& CULLEN, M.R. 2017. Occupation and risk for injuries. In: MOCK, C.N., NUGENT, R., KOBUSINGYE, O. \& SMITH, K.R. (eds.). Injury prevention and environmental health. $3^{\text {rd }}$ ed. The International Bank for Reconstruction and Development / The 
World Bank. Chapter 6. Washington (DC). [Online] Available: https://pubmed.ncbi.nlm.nih.gov/30212110/. [Accessed 20/1/2020].

ALBERT, B. 2004. Disability KaR Research Project: Enabling disabled people to reduce poverty. Briefing note: The social model of disability, human rights and development [Online] Available: www.disabilitykar.net [Accessed: 21/11/2019].

ALSTON, M. \& BOWLES, W. 2003. Research for caring professions: An introduction to methods. London: Routledge Taylor \& Francis Group.

BABBIE, E. \& MOUTON, J. 2010. The practice of social research $10^{\text {th }}$ ed. Cape Town: Oxford University Press Southern Africa.

BARON, S., PHILLIPS, R. \& STALKER, K. 1996. Barriers to training for disabled social work students. Disability and Society, 11:361-379.

BEZERRA, M.A., PAULO, J., SUELY, K. \& SILVA, Q. 2015. Support networks and people with physical disabilities: Social inclusion and access to health services. Public Health Science, 20(1):175184.

BLAUWET, C. 2018. Are you my doctor? Towards a world where a physician in a wheelchair is no big deal. [Online] Available: https://stanmed.stanford.edu/listening/time-that-doctor-with-disabilityseen-ordinary.html [Accessed 4/3/2021].

BONACCIO, S., CONNELLY, C.E., GELLATLY, I.R., JETHA, A. \& MARTIN-GINIS, K.A. 2020. The participation of people with disabilities in the workplace across the employment cycle: Employer concerns and research evidence. Journal of Business and Psychology, 35(2):135-158.

BRADLEY, G. 2008. The induction of newly appointed social workers: Some implications for social work educators. Social Work Education, 27(4):349-365.

BRAUN, V. \& CLARKE, V. 2006. Using thematic analysis in psychology. Qualitative Research in Psychology, 3(2):77-101.

BRYMAN, A. 2012. Social research methods. $4^{\text {th }}$ ed. Oxford: Oxford University Press.

COPELAND, J., CHAN, F., BEZYAK, J. \& FRASER, R.T. 2010. Assessing cognitive and affective reactions of employers toward people with disabilities in the workplace. Journal of Occupational Rehabilitation, 20(4):427-434.

CRAWSHAW, M. 2010. Disabled people's access to social work education--Ways and means of promoting environmental change. Social Work Education, 21(5):503-514.

CRESWELL, J.W. 2009. Research design: Qualitative, quantitative, and mixed methods approaches. $3^{\text {rd }}$ ed. London: Sage Publications.

DE VOS, A.S., STRYDOM, H., FOUCHE, C.B. \& DELPORT, C.S. (eds.). 2011. Research at grassroots. To the social sciences and human service professions. (4th ed). Cape Town: Van Schaik Publishers.

DLANGAMANDLA, V.P. 2010. The experiences of social workers regarding the implementation of a developmental social welfare approach within the Department of Social Development Gauteng Province. Pretoria: University of Pretoria. (MASW thesis)

DONNELLY, K. \& JOSEPH, J. 2012. Disability employment in the hospitality industry: Human resources considerations. Cornell HR Review. [Online]. Available: https://digitalcommons.ilr.cornell.edu/chrr/27/ [Accessed: 04/07/2020].

ESCAMILLA, A. 2017. Accommodating students with physical disabilities in higher education. Encyclopedia of Social Work. [Online] Available: https://oxfordre.com/socialwork/view/10.1093/acrefore/9780199975839.001.0001/acrefore- 
9780199975839-e-1219. [Accessed: 23/04/2019].

FARUKUZZAMAN, M. \& RAHMAN, A.H.M.M. 2019. Communication pattern in social work practice: A conceptual framework. International Journal of Research in Sociology and Anthropology (IJRSA), 5(2):32-43.

FREIDEL, C.R. 1997. A survey on work experiences of practicing social workers who are disabled. San Bernardino: California State University. (M thesis)

GIDA, P. \& ORTLEPP, K. 2007. Employment of people with disabilties: Implications for human resource management practice. Acta Commercii, 7(1):135-150.

GOLIATH, J. 2018. Management functions of frontline social workers supervising social auxiliary workers. Stellenbosch: Stellenbosch University. (M thesis).

GROSSMAN, B.R. \& MAGANA, S. 2016. Introduction to the special issue: Family support of persons with disabilities across the life course. Journal of Family Social Work, 19(4):237-251.

GUSTAFSSON, J., PERALTA, J.P. \& DANERMARK, B. 2014. The employer's perspective: Employment of people with disabilities in wage subsidized employments. Scandinavian Journal of Disability Research, 16(3):249-266.

HARGREAVES, J., DEARNLEY, C., WALKER, S. \& WALKER, L. 2014. The preparation and practice of disabled health care practitioners: Exploring the issues. Innovations in Education and Teaching International, 51(3):303-314.

HEALY, J., TILLOTSON, N., SHORT, M. \& HEARN, C. 2015. Social work field education: Believing in supervisors who are living with disabilities. Disability \& Society, 30(7):1087-1102.

JAYASOORIA, D., KRISHNAN, B. \& OOI, G. 1997. Disabled people in a newly industrialising economy: Opportunities and challenges in Malaysia. Disability \& Society, 12(3):455-463.

KAPLAN, D. 2000. The definition of disability: Perspective of the disability community. Journal of Health Care and Policy, 3(2):352-364.

KULKARNI, M. \& VALK, R. 2010. Don't ask, don't tell: Two views on human resource practices for people with disabilities. IIMB Management Review, 22(4):137-146.

KUMAR, R. 2005. Research methodology: A step-by-step guide for beginners. 3rd ed. London: SAGE Publications.

KWAN, C.K. \& REUPERT, A. 2019. The relevance of social workers' personal experiences to their practices. The British Journal of Social Work, 49(1):256-271.

LEWIS, R., DOBBS, L. \& BIDDLE, P. 2013. 'If this wasn't here I probably wouldn't be': Disabled workers' views of employment support. Disability \& Society, 28(8):1089-1103.

MACDONALD-WILSON, K.L., RUSSINOVA, Z., ROGERS, E.S., LIN, C.H., FERGUSON, T., DONG, S. \& MACDONALD, M.K. 2011. Disclosure of mental health disabilities in the workplace. In: SCHULTZ, I. \& ROGERS, E. (eds.). Work accommodation and retention in mental health. New York: Springer.

MAK, M.A. 2013. Supervision training needs: Perspectives of social work supervisees. St. Paul, Minnesota: St. Catherine University. (M thesis)

MALATJI, H. \& DUBE, N. 2017. Experiences and challenges related to residential care and the expression of cultural identity of adolescent boys at a child and youth care centre (CYCC) in Johannesburg. Social Work (South Africa), 53(1):109-126.

MASHIGO, B.P. 2007. Social workers' experiences on the transformation of social welfare from remedial approach to developmental approach. Port Elizabeth: Nelson Mandela Metropolitan 
University. (MASW thesis)

MCCOLL, M.A., FOSTER, D., SHORTT, S.E., HUNTER, D., DORLAND, J., GODWIN, M. \& ROSSER, W. 2008. Physician experiences providing primary care to people with disabilities. Healthcare Policy, 4(1):129-147.

MENDES DE LEON, C.F., GOLD, D.T., GLASS, T.A., KAPLAN, L. \& GEORGE, L.K. 2001. Disability as a function of social networks and support in elderly African Americans and whites: The Duke EPESE 1986-1992. The Journals of Gerontology: Series B, 56(3):S179-S190.

MONETTE, D.R., SUlLIVAN, T.J. \& DEJONG, C.R. 2005. Applied social research: A tool for the human services. (6th ed). Australia: Thomson Brooks/Cole.

NELSON, C. 2015. Effective observation in social work practice. Practice, 27(4):292-294.

NHEDZI, F. \& MAKOFANE, M. 2015. The experiences of social workers in the provision of family preservation services. Social Work/Maatskaplike Werk, 50(3):354-378.

OLD, J. 2017. Book review: Effective observation in social work practice, Maureen O'Loughlin and Steve O'Loughlin (eds.). The British Journal of Social Work, 47(3):959-961.

OLIVER, M. 1983. Social work with disabled people. Basingstoke: Macmillan.

POTGIETER, I.L., COETZEE, M. \& XIMBA, T. 2017. Exploring career advancement challenges people with disabilities are facing in the South African work context. SA Journal of Human Resource Management, 15(0):1-11.

REPUBLIC OF SOUTH AFRICA (RSA). 1998. Employment Equity Act (No. 55 of 1998). Pretoria: Government Printers. [Online] Available: http://www.labour.gov.za/DocumentCenter/Acts/Employment\%20Equity/Act\%20\%20Employment\%20Equity\%201998.pdf [Accessed: 4/3/2021]

ROYSE, D. 2008. Research methods in social work. (5th ed). Australia: Thomson Brooks/Cole.

SCHURINK, W., FOUCHE, C.B. \& DE VOS, A.S. (2011). Qualitative data analysis and interpretations. In: DE VOS, A.S., STRYDOM, H., FOUCHE, C.B. \& DELPORT, C.S.L. (eds.). Research at grassroots. To the social sciences and human service professions. $4^{\text {th }}$ ed. Cape Town: Van Schaik Publishers: 397-423.

STATISTICS SOUTH AFRICA. 2014. Census 2011: Profile of persons with disabilities in South Africa. Pretoria: Statistics South Africa. Available: https://www.statssa.gov.za/publications/Report-0301-59/Report-03-01-592011.pdf [Accessed: 4/3/2021].

STATISTICS SOUTH AFRICA. 2016. Community Survey 2016 Statistical release. Pretoria: Statistics South Africa. Available: http://cs2016.statssa.gov.za/wp-content/uploads/2016/07/NT-30-06-2016RELEASE-for-CS-2016-_Statistical-releas_1-July-2016.pdf [Accessed 4/3/2021].

STRYDOM, H. 2011. Sampling in the quantitative paradigm. In: DE VOS, A.S., STRYDOM, H., FOUCHE, C.B. \& DELPORT, C.S.L. (eds.) Research at grassroots. To the social sciences and human service professions. $4^{\text {th }}$ th ed. Cape Town: Van Schaik Publishers: 222-235.

STRYDOM. H. \& DELPORT, C.S. 2011. Sampling and pilot study in qualitative research. In: DE VOS, A.S., STRYDOM, H., FOUCHE, C.B. \& DELPORT, C.S.L. (eds.). Research at grassroots. To the social sciences and human service professions. $4^{\text {th }}$ ed. Cape Town: Van Schaik Publishers: 327-332.

TA, T.L. \& LENG, K.S. 2013. Challenges faced by Malaysians with disabilities in the world of employment. Asia Pacific Disability Rehabilitation Journal, 24(1):6-21.

VAN STADEN, A.F. 2011. A strategy for the employment of persons with disabilities. Pretoria: University of Pretoria. (PhD thesis) 
WEGNER, L. 2011. Department of Health, South Africa. National guidelines for the development of health promoting schools / Sites in South Africa. South African Journal of Occupational Therapy, 41(1):193-211.

WORLD HEALTH ORGANIZATION. 2011. World Report on Disability. [Online] Available: www.who.int/teams/noncommunicable-diseases/disability-and-rehabilitation/world-report-on-disability [Accessed: 25/01/2019].

XIMBA, T. 2016. Career advancement challenges facing people with disability in South Africa. Pretoria: University of South Africa. (M thesis)

ZUNKER, V.G. 2006. Career counselling: A holistic approach. $7^{\text {th }}$ ed. Pacific Grove, CA: Thomson Brooks/Cole. 